\title{
A Possible Source for The Coercivity of Ilmenite-Hematite Minerals
}

\author{
Ronald T. MERRILL \\ Department of Oceanography, University of Washington
}

(Received April 9; revised June 8, 1968)

\begin{abstract}
Large coercivities of some ilmenohematite minerals are probably due to magnetostrictive effects associated with exsolution.
\end{abstract}

\section{Coercivity in Paleomagnetic Studies}

The success of any pursuit in Paleomagnetism is in part based on the remarkable stability of some remanent magnetizations. Usually it is tacitly assumed that magnetic stability with time is directly related to the coercivity measured in the laboratory. This is not an obvious assumption since coercivity may be time dependent. For example defects (dislocations, lattice impurities, etc.), impeded by domain walls during migration, will tend to accumulate in the neighborhood of the wall, thereby enhancing the microscopic coercivity (i.e. a larger magnetic field is required to move the wall). It remains to be seen whether there is significant migration of defects below the Curie temperature in geologic time. In any case, before the origin and properties of remanence can be well understood, it seems necessary to obtain a better understanding of the origin of coercivity in various minerals. Such an attempt is undertaken in this paper with regard to coercivities in ilmenite-hematite compositions.

\section{Coercivity in Ilmenite-Hematite Minerals}

The bulk coercivity of hematite is around 400 oersteds and increases with increase in ilmenite in the lattice until a maximum (800 to 900 oersteds) is reached near 20 to 30 mole percent ilmenite in hematite (Nagata, 1967). The NRM of many ilmenohematites in rocks have coercivities which exceed 1000 oersteds (e.g.. Carmichael, 1961). Both magnetocrystalline and shape anisotropy energies are too small to explain these high coercivities: the maximum demagnetizing field is $4 \pi I_{s}$, where the saturation magnetization, $I_{s}$, is only about $2 \mathrm{emu} / \mathrm{cc}$ (Lindsley et al., 1966), and the coercivity resulting from magnetocrystalline anisotropy energy is around 60 oersteds (Ande son, 1954). Since Smith and Fuller (1967) have given reasons why exchange anisotropy is also inadequate, we are left with magnetostrictive anisotropy as being the only energy capable of producing the observed values.

Smith and Fuller (1967) have suggested that the hard coercivity of hematite originates in a defect moment. Citing the differential thermal analysis of Aharoni et al. (1962) and thermal-magnetic curves obtained by Kawai (for an ilmenohematite with 8 mole\% ilmenite 
in solid solution), they further suggested that this defect moment originates at $725^{\circ} \mathrm{C}$ while a spin canted imoment originates at $675^{\circ} \mathrm{C}$. However, Aharoni et al. (1963) published an erratum which states that there is only evidence for the existence of one transition $\left(690^{\circ} \mathrm{C}\right)$. Moreover Smith and Fuller (1967, Figure 2) have presented evidence that Kawai's thermal curves are not reproducible. Coe (1967) has shown that numerous factors can give rise to such curves (including changes in the Curie or Néel point), i.e. a unique interpretation of Kawai's data seems difficult. Mössbauer work by Freier et al. (1962) and Gilad et al. (1963) also indicates that only one transition exists (Freier et al. place this transition at $690^{\circ} \mathrm{C}_{ \pm 10^{\circ}}$ while Gilad et al. place it at $682^{\circ} \mathrm{C}_{ \pm 10^{\circ}}$ ). Nevertheless the suggestion by Smith and Fuller (1967) attributing the high coercivity of hematite to a defect moment does seem to be supported by low temperature measurements of Kobayashi and Smith (1965). Perhaps both a spin canted and a defect moment originate at, or near, the same temperature $\left(690^{\circ} \mathrm{C}\right)$. Although strain associated with defects (and therefore hypothesized defect moments) should change the Néel point, this change is probably quite small (Patrick, 1954).

A ingenious etching experiment performed on the Allard Lake rocks by Carmichael $(1959,1961)$ provides a clue to a possible source of high coercivity in some ilmenohematites. His experiment demonstrates that the remanence resides in the smaller of two sets of exsolved ilmenohematite lamellae. The calculation which follows will show that large internal strains are associated with exsolution lamellae; the origin of these strains lies in the different lattice dimensions of the two exsolved phases. Because a much larger percentage of strain per unit volume exists in small, thin lamellae than in large, thick ones, magnetostriction is probably responsible for the phenomena observed by Carmichael.

Consider a rectangular prism of exsolved $\mathrm{Fe}_{2} \mathrm{O}_{3}$ enclosed in $\mathrm{FeTiO}_{3}$. The choice of a rectangular cross-section to approximate an exsolution lamella allows one to consider only boundaries which are either parallel or perpendicular to the basal splane. In the following calculation the $z$ axis coincides with the $c$ crystallographic axis (perpendicular to the basal plane) and the $x$ axis coincides with an " $a$ " axis.

For a crystal with rhombohedral symmetry, the strain energy function, $W$, is (Love, 1944):

$$
\begin{aligned}
W & =\frac{1}{2} c_{11} e_{x x}{ }^{2}+c_{12} e_{x x} e_{y y}+c_{13} e_{x x} e_{z z}+2 c_{15} e_{x x} e_{z x} \\
& +\frac{1}{2} c_{11} e_{y y}{ }^{2}+c_{13} e_{y y} e_{z z}-2 c_{15} e_{y y} e_{z x}+\frac{1}{2} c_{33} e_{z z}{ }^{2} \\
& +2 c_{44} e_{y z}{ }^{2}+2 c_{44} e_{z x}{ }^{2}-4 c_{15} e_{y z} e_{x y}+\left(c_{11}-c_{12}\right) e_{x y}{ }^{2}
\end{aligned}
$$

where $c_{i}$ are the moduli of elasticity and $e_{i j}$ are the usual components of the strain tensor. Using the relationship $\sigma_{i j}=\frac{\partial W}{\partial e_{i j}}$ one finds the appropriate components of stress:

$$
\begin{aligned}
\sigma_{x x} & =c_{11} e_{x x}+c_{12} e_{y y}+c_{13} e_{z z}+2 c_{15} e_{z x} \\
\sigma_{y y} & =c_{11} e_{y y}+c_{13} e_{z z}-2 c_{15} e_{z x}
\end{aligned}
$$

$\sigma_{z z}$ is not important since a very large magnetocrystalline anisotropy energy confines the 
magnetization to the basal plane (Néei and Pauthenet, 1952).

Because the moduli of elasticity for $\mathrm{FeTiO}_{3}$ are not known, I will assume that the strain originating at the boundary is equally accommodated by the two phases. This approximation seems to be better than assuming that the $\mathrm{FeTiO}_{3}$ is completely rigid: such an assumption would result in an increase in the calculated coercivity. Although the distance over which the strain is accommodated is not well known, it is sometimes assumed to be only one lattice constant (Fine, 1964). However, because we are only interested in equating magnetic energy in a volume element to magnetostrictive energy in estimating the coercivity, nothing is lost by assuming that the strain is distributed throughout the lamella. The lattice parameters for pure $\mathrm{Fe}_{2} \mathrm{O}_{3}$ and $\mathrm{FeTiO}_{3}$ are, respectively, $a_{\text {hex }}=5.0345, c_{\text {hex }}=13.745$ and $a_{\text {nex }}=5.089, c_{\text {hex }}=14.163$. These parameters vary linearly between $\mathrm{FeTiO}_{3}$ and $\mathrm{Fe}_{2} \mathrm{O}_{3}$ (Ishikawa and Akimoto, 1958). Thus, it is clear that appropriate modifications of the following calculation can easily be made for more realistic compositions (the solvus for this system has been published by Uyeda, 1958 and Carmichael, 1961). Recalling that only one-half of the strain is accommodated by the $\mathrm{Fe}_{2} \mathrm{O}_{3}$, the strains are:

$$
\begin{aligned}
e_{x x} & =\frac{1}{d_{a}}\left(\frac{1}{2}\right) \frac{5.089-5.035}{5.089}=\frac{0.00530}{d_{a}} ; e_{y y}=\frac{0.2184}{d_{a}} ; \\
e_{z z} & =0.01460 / d_{c} \text { and } e_{i j}=0 \text { for } i \neq j \text { (from symmetry). }
\end{aligned}
$$

$2 d_{a}$ and $2 d_{c}$ respectively represent the dimensions of the lamella in the $a_{\text {hex }}$ and $c_{\text {hex }}$ directions. In order to calculate the stresses from equations 2 and 3 one must assume some dimensions for the lamella. If $\frac{d_{a}}{d_{c}}=\frac{a_{\text {hex }}}{c_{\text {hex }}} d_{a}=\frac{1}{2} \mu$, then $\sigma_{x x}=27.16 \times 10^{6} \mathrm{dynes} / \mathrm{cm}^{2}$ and $\sigma_{y y}=$ $76.12 \times 10^{6}$ dynes $/ \mathrm{cm}^{2}$, where I have used the values (Clark, 1966): $c_{11}=2.42 \times 10^{12} \mathrm{dynes} / \mathrm{cm}^{2}$; $c_{12}=0.55 \times 10^{12}$ dynes $/ \mathrm{cm}^{2}$ and $c_{13}=0.16 \times 10^{12}$ dynes $/ \mathrm{cm}^{2}$.

The only measurements of magnetostriction which this author is aware of come from Urquhart and Goldman (1956). By changing the direction of an external field in the basal plane of hematite and measuring the resulting strain with a gauge placed in the [112] direction, they found that the strain was described by:

$$
\frac{\Delta L}{L}=8 \times 10^{-6} \sin ^{2} \theta
$$

where $\theta$ is the angle between the external field and the [112] direction. Equating this to $3 / 2 \lambda\left(1-\cos ^{2} \theta\right)$, we find that $\lambda$ is $16 / 3 \times 10^{-6}$. Thus at present, the best estimate for the coercive force, $H_{c}$, obtained by equating the magnetostrictive energy, $3 / 2 \lambda\left(\sigma_{y y}-\sigma_{x x}\right)$, to the magnetic energy, $I_{s} \cdot H_{c}$, is $H_{c} \approx 200$ oersteds, for $I_{s}$, the saturation magnetization, equal to $2 \mathrm{emu} / \mathrm{cc}$.

The value for coercivity depends greatly on the dimensions of the lamellae. The calculated coercivity of ilmenohematite $\left(0.2 \mathrm{FeTiO}_{3} 0.8 \mathrm{Fe}_{2} \mathrm{O}_{3}\right)$ exsolved in hemoilmenite $\left(0.8 \mathrm{FeTiO}_{3} 0.2 \mathrm{Fe}_{2} \mathrm{O}_{3}\right)$ is around 450 oersteds for the small lamellae of the Allard Lake rocks in which $\frac{d_{a}}{d_{c}} \approx \frac{a_{\mathrm{hex}}}{3 c_{\mathrm{hex}}}$ and $d_{a} \approx 0.1 \mu$ (Carmichael, '1961). (In this last calculation I assumed that both the moduli of elasticity and the value for $\lambda$ for hematite hold for ilmenohematite. The lattice parameters used came from the data of Ishikawa and Akimoto, 1958). The larger Allard Lake lamellae, which have dimensions roughly 10 times the smaller, have a 
calculated coercivity around 45 oersteds. These results are smaller than those reported: the measured coercivity is less than 200 oersteds for the larger lamellae and around 1400 oersteds for the smaller lamellae (Carmichae", 1961).

The difference between the reported and calculated coercivities may be due partly to the rectangular lamellae model assumed, (a "rounding off" of the corners would decrease the total volume and increase the calculated coercivity). However, it is likely that most of this difference originates because the hard component of magnetization resides in lamallae which are smaller than average. Indeed the high reported coercivities are obtained by assuming lamellae which are $1 / 3$ the dimensions used in the above calculations. Note also that unless there is a greater proportion of defects in the smaller lamellae than in the larger, magnetostrictive effects associated with defects (a likely source of coercivity in pure hematite) cannot account for the difference between the observed and calculated coercivities.

\section{Conclusions}

Although the coercivity of pure hematite is not yet well understood, it seems likely that it is derived from magnetostrictive anisotropy associated with defects. The coercivities of many ilmenohematites are larger than those in pure hematite and are probably derived from magnetostrictive anisotropy associated with exsolution and defects. On the other hand, Dickson et al. (1966) have shown that large coercivities in the magnetite-ulvospinel series can originate from shape anisotropy. The role coercivity plays in TRM theories is controversial (e.g. Verhoogen, 1959; Stacey, 1963; Dickson et al., 1966). However it now seems that any adequate theory for TRM will have to consider the likelihood that large coercivities originate in different ways in different minerals. This consideration requires that an adequate theory for TRM treat coercivity in a general manner or that several theories be abvanced to explain the origin of TRM in different minerals.

\section{Acknowledgements}

I thank H. Schechter and R. Ingalls of the University of Washington for pointing out data on the Néel point of hematite. J. Verhoogen of the University of California at Berkeley and Subir Banerjee of Ampex Corporation made helpful comments on the coercivity calculations. Contribution Number 467. Department of Oceanography, University of Washington.

\section{References}

Aharoni, A., E.H. Frei, and M. Schieber, Curie Point and Origin of Weak Ferromagnetism in Hematite, Phys. Rev., 127, 439, 1962.

Aharoni, A., E.H. Frei, and M. Schieber. Curie Point and Origin of Weak Ferromagnetism in Hematite Erratum, Phys. Rev., 129, 2835, 1963.

Anderson, P.W., F.R. Merritt, J. P. Remeika, and W.A. Yager, Magnetic Resonance in $\alpha \mathrm{Fe}_{2} \mathrm{O}_{3}, P h y s$. Rev., 93, 717-718, 1954.

Carmichael, C.M., Remanent Magnetism of the Allard Lake Ilmenites, Nature, 183, 1239-1241, 1959.

Carmichael, C.M., The Magnetic Properties of Ilmenite-Hematite Crystals, Proc. Roy. Soc., London, A, 
263, 508-530, 1961.

Coe, R., The Determination of Paleo-Intensities of the Earth's Magnetic Field with Emphasis on Mechanisms which Could Cause Non-Ideal Behavior in Thellier's Method, J. Geomag. and Geoelect., 19, 157-179, 1967.

Dickson, G.O., C.W. Everitt, L.G. Parry, and F.D. Stacey, Origin of T.R.M., Earth and Plan. Sci. Letters, 1, 222-224, 1966.

Fine, M., Phase Transformation in Condensed Systems, MacMillan Co., New York, 1964.

Freier,S., M. Greenshpan, P. Hillman, and H. Shechter, The Antiferromagnetic Curie Point in $\alpha \mathrm{Fe}_{2} \mathrm{O}_{3}$, Phys. Letters, 2, 191-193, 1962.

Gilad, P., M. Greenshpan. P. Hillman and H. Schechter, On the Curie Temperature of $\alpha \mathrm{Fe}_{2} 0_{3}, P h y s$. Letters, 7, 239-240, 1963.

Ishikawa, Y., and S. Akimoto, Magnetic Property and Crystal Chemistry of Ilmenite $\left(\mathrm{MeTiO}_{4}\right)$ and Hematite $\left(\mathrm{Fe}_{2} \mathrm{O}_{3}\right)$ System, 1. Crystal Chemistry J. Phys. Soc. Japan, 13, 1110-1118, 1958.

Kobayashi, K., and R.W. Smith, Reversible Susceptibility of Hematite Carrying Various Types of Remanent Magnetization and Memory, J. Geomag. and Geoelect., 17, 325-337, 1965.

Lindsley, D.H., G.E. Andreasen and J.R. Balsley, Magnetic Properties of Rocks and Minerals, in Handbook of Physical Constants, edited by S.P. Clark, Geol. Soc. Amer. Memoir, 1966.

Love, A.E.H., The Mathematical Theory of Elasticity, 4th Ed., Dover Pub., 159-160, 1944.

Nagata, T., Rock Magnetism, 2nd Ed., Maruzen, Tokyo, 1961.

Nagata, T., Identification of Magnetic Minerals in Rocks Using Methods Based on Their Magnetic Properties, in Methods in Paleomagnetism, edited by Collinson, D.W., K.M. Creer and S.K. Runcorn, Elsevier Pub. Co., Amsterdam, 1967.

Néel, L. and R. Pauthenet, Etude Thermomagnetique d'un Monocristal de $\mathrm{Fe}_{2} \mathrm{O}_{3}$ C.R. Acad.Sci., Paris, 234, 2172-2174.

Patrick, L., The Change of Ferromagnetic Curie Points with Hydrostatic Pressure, Phys. Rev., 93, 384392, 1954.

Smith, R.W., and M. Fuller, Alpha-Hematites Stable Remanence and Memory, Sci., 156, 1130-1133, 1967.

Stacey F.D., The Physical Theory of Rock Magnetism, Adv. Phys., Suppl. Phyl. Mag. London, 12, 45143, 1963.

Urquhart, H.M.A., and J.E. Goldman, Magnetostrictive Effects in an Antiferromagnetic Hematite Crystal, Phys. Rev., 101, 1443-1450, 1956.

Uyeda, S., Thermo-Remanent Magnetism as a Medium of Paleomagnetism with Special Reference to Reverse Thermo-Remanent Magnetism, Jap. J. Geophys., 2, 1-123, 1958.

Verhoogen, J., The Origin of Thermoremanent Magnetization, J. Geophys. Res., 64, 2241-2449, 1959. 